\title{
Age and Cultural Differences in Self-Perceptions of Mastery Motivation and Competence in American, Chinese, and Hungarian School Age Children
}

\author{
Krisztian Jozsa, ${ }^{1}$ Jun Wang, ${ }^{2}$ Karen Caplovitz Barrett, ${ }^{3}$ and George A. Morgan ${ }^{4}$ \\ ${ }^{1}$ Institute of Education, University of Szeged, 30-34 Petöfi Sándor sgt., Szeged 6722, Hungary \\ ${ }^{2}$ Institute for Applied Research in Youth Development, Tufts University, 307 Lincoln Filene Building, Medford, MA 02155, USA \\ ${ }^{3}$ Human Development and Family Studies, Colorado State University, 311 Behavioral Sciences Building, \\ Fort Collins, CO 80523-1570, USA \\ ${ }^{4}$ School of Education, Colorado State University, 240 Education Building, Fort Collins, CO 80523-1588, USA
}

Correspondence should be addressed to Krisztian Jozsa; jozsa@sol.cc.u-szeged.hu

Received 30 June 2014; Revised 24 November 2014; Accepted 5 December 2014; Published 29 December 2014

Academic Editor: Glenda Andrews

Copyright (C) 2014 Krisztian Jozsa et al. This is an open access article distributed under the Creative Commons Attribution License, which permits unrestricted use, distribution, and reproduction in any medium, provided the original work is properly cited.

We examined age differences in self-perceptions of five dimensions of mastery motivation and also of competence in American, Chinese, and Hungarian children and teens. Participants included 200 Americans, 1,465 Chinese, and 8,175 Hungarians from 7 to 19 years of age. The Dimensions of Mastery Questionnaire provides comparable data across these different cultures as indicated by very similar factor structures and reasonably good internal consistency reliabilities for the scales. Across all three cultures, there was the expected decline from primary to secondary school in total persistence and the four instrumental mastery motivation scales, except for social persistence with adults in the American sample. Mastery pleasure did not decline in the American and Chinese samples but declined in the Hungarian sample. Self-perceived competence did not decline significantly in the American sample or in the Hungarian sample from age 11 to 17; however, competence self-ratings declined in the Chinese sample. The three cultures were compared at 11 and 16 . Although there were some significant differences, small effect sizes indicated that the level of motivation was similar for each culture at each age. The other literature provides clues about why the declines occur in all three cultures and why there are some differences among cultures.

\section{Introduction}

Several classic as well as recent studies have found a decline in intrinsic motivation as American children go through middle childhood and into adolescence [1-4]. Here we explore whether a comparable decline is manifest in five aspects of a related construct, students' mastery motivation, and in their perceived competence, in three quite different cultures and school systems: American, mainland Chinese, and Hungarian.

1.1. Mastery Motivation. The US National Academy of Sciences report From Neurons to Neighborhoods identified mastery motivation, the drive to explore and master one's environment, as a key developmental concept, which should be included as part of a child's evaluation [5]. One definition is that mastery motivation stimulates an individual to attempt in a focused and persistent manner to solve a problem or master a skill or task which is at least moderately challenging for him or her [6]. Other definitions have emphasized the importance of having a goal and displaying persistent attempts to attain it in the face of moderate uncertainty about whether it can be achieved [6].

We distinguish the motive to master skills and solve problems from the somewhat related concept of intrinsic motivation. The two concepts are different in terms of focus and measurement. Although mastery motivation has usually been assumed to be initially intrinsic in infants, the focus of mastery motivation research has been on a child's persistent attempts to master challenging tasks, whether the reward comes from within or whether extrinsic rewards are offered [7]. In contrast, the intrinsic motivation literature places little 
emphasis on mastery, focusing instead on the source (internal or external) of the motivation.

The study of mastery motivation is usually traced back to White's effectance motivation theory [8]. He challenged researchers to view curiosity, play, and exploration as being based on a motive to have an effect on one's environment. This "effectance motivation" was thought to be based on children's intrinsic tendency to interact with the environment and to continually adapt to it. White theorized that effectance motivation was maintained by feelings of efficacy or pleasure that came from one's sense of mastery of the physical and/or social environment.

Two separate groups of investigators one led by Harter [2] and one led by Yarrow et al. [9] attempted to translate White's theory of effectance motivation into specific measures and hypotheses that could be researched empirically.

Harter's research and theory focused on intrinsic versus extrinsic motivation in school age children. She [2] developed a self-report instrument to assess intrinsic versus extrinsic motivation in the classroom, which has been used in much of this line of research. Harter's questionnaire assesses five aspects of intrinsic versus extrinsic motivation in the classroom for 3rd to 9th grade American students. In four of these aspects, children must represent themselves as being intrinsic or extrinsic in orientation, after which they rate the degree to which this is true. Children also indicate whether they like challenge or prefer easy work and then indicate how much this is true. The five scales are (a) preference for challenge versus preference for easy work, (b) intrinsic curiosity versus teacher approval, (c) independent mastery attempts versus dependence on the teacher, (d) independent judgment versus reliance on the teachers' judgment, and (e) internal versus external criteria for success/failure. None of these scales focuses on how much children engage in mastery tasks, how long they persist in trying to master challenging tasks, or how much they derive pleasure from solving problems or learning new skills. Nor do the scales highlight potential differences in motivation in different domains of development, such as cognitive versus motor versus social development. Rather, the main emphasis is on whether the motivation for engaging in the tasks arises from within the child versus from the teacher.

In contrast, Yarrow and colleagues' work mainly involved observation of mastery-oriented behaviors in infants and young children, rather than questionnaire data. Until recently, mastery motivation was studied primarily with object-oriented or cognitive tasks developed for infants and preschool children and persistence at such tasks was the main way of operationalizing the concept [6]. Now, the mastery motivation construct and measurement efforts have been expanded in several ways. First, in addition to persistence, an instrumental aspect of mastery motivation, theory and research have emphasized the importance of affective aspects, especially mastery pleasure, which is a positive affect during task-directed behavior and/or immediately after a solution [10]. In addition, some research has included an affective aspect with potential negative effects on mastery-related behavior, negative reactions to failure [10]. Further, the concept and measures were expanded to include mastery of gross motor/athletic skills and social interactions. Social mastery motivation focuses on mastery of interactions with both child peers and adults [6].

More recently, researchers from this line of research developed a parent-report instrument and then a self-report instrument to obtain information similar to that derived from such behavioral observations. The resulting measure, the Dimensions of Mastery Questionnaire (DMQ), [11], in contrast to Harter's measure, did not require the respondent to judge whether the behavior was intrinsically versus extrinsically motivated. The DMQ was developed to assess mastery motivation with parent (or teacher) report versions for infancy through teen age and a self-report version for children from elementary through high school. It was believed that it is difficult for parents of children and even for the children themselves to truly know whether they are engaging in focused task-related behavior in order to gain external rewards such as approval from others versus in order to independently master the task. Moreover, it seems likely that children engage in mastery-oriented activity for both reasons in many cases. Recent research has suggested that intrinsic and extrinsic motivation are relatively orthogonal [3]. The DMQ also included a greater focus on several domains of mastery (i.e., cognitive, social and gross motor) because it seemed likely that children can be more or less masteryoriented in different domains of development. The DMQ, thus, assesses five aspects or dimensions of mastery motivation and also provides a quick measure of self-perceived competence or ability.

Using the DMQ, the measurement of mastery motivation was expanded to include school age children and to include other cultures and languages [12,13]. Approximately 20,000 children, from infants to teens, in a variety of cultures have been rated or rated themselves with the Dimensions of Mastery Questionnaire. This expansion to new age groups and cultures set the stage for studies of developmental changes in mastery motivation and of the relationship of mastery motivation to self-perceived competence. A recent longitudinal study found that $61 \%$ of Hungarian school children showed a substantial decline on self-ratings of cognitive persistence, one key aspect of mastery motivation, from 4 th to 8 th grade [7]. Only 6\% showed a substantial gain in cognitive persistence, and 34\% neither increased nor declined.

Several other recent Hungarian studies on motivation and self-concept provide useful background for the current studies. Jozsa [14] has developed subject-specific mastery motivation scales using items similar to those in the DMQ but focused on children's motivation to master English and German as foreign languages. Interestingly, there was a decline in motivation to master German similar to the decline found in cognitive persistence. However there was no decline from 6th to 10th grade in motivation to master English, perhaps because Hungarian children place a high value on understanding American popular culture.

In other Hungarian studies Jozsa and colleagues have developed computer based versions of the DMQ and selfconcept scales $[15,16]$. The computer read the questionnaires to the children and provided visual aids so that they could be used with younger children. The reliability and validity of the computer based questionnaires were good and similar to 
that of the typical paper and pencil version. Second graders had no trouble answering the computer version of the DMQ, which showed no decline between 2nd and 4th grade for these Hungarian children. The authors also found no decline in general self-concept from 2nd to 10th grade. However math self-concept declined significantly, which is similar to what Gottfried et al. [1] found with her Academic Intrinsic Motivation Mathematics Scale.

\subsection{Declines in Intrinsic Motivation in American Children.} Although mastery motivation and intrinsic motivation are different concepts, they are potentially related, and research on intrinsic motivation provided one stimulus for the current study. Several classic studies showed age declines in intrinsic motivation as children enter middle and high school, similar to findings for Hungarian children's mastery motivation described in the last section. Harter's questionnaire Children's Intrinsic Versus Extrinsic Motivation in the Classroom [2] was used or modified in a number of studies showing this decline. Across grades 3-9 there was a shift from intrinsic to extrinsic scores on the scales involving motivation. Lepper et al. [3], in a cross-sectional study using a measure that did not pit intrinsic against extrinsic motivation, found the expected significant linear decrease in self-reported intrinsic motivation. However, in contrast to Harter, Lepper et al. did not find an increase in extrinsic motivation from 3 rd grade to 8th grade. This study highlighted the importance of further assessing what types of motivation do and do not decline during this age period.

Gottfried [17] developed scales of academic intrinsic motivation in the classroom that assess intrinsic motivation in several subject areas (e.g., reading and math) as well as for school in general. She has published a series of studies using this instrument in part to study longitudinal changes in aspects of academic intrinsic motivation. For example, Gottfried et al. [1] found a decline in American children's academic intrinsic motivation from 9 to 17 years for math, science, reading, and school in general, but not for social studies. This decline was greatest for math. Gottfried et al. $[4,18]$ have more recently shown that reduced math achievement predicted this steep decline for math intrinsic motivation, which, in turn, predicted educational attainment at age 29, demonstrating its importance. Moreover, her work shows the potential importance of separately examining different domains of mastery. However, her domains were all school-related and, thus, could not provide information about whether motivational decline was limited to schoolrelated motivation and/or due to school-related changes from elementary to high school.

1.3. Motivational Age Differences in Other Cultures. Similar declines have been found in several motivational constructs in several other cultures. Hong Kong children's intrinsic motivation and motivation for reading declined from elementary school to high school [19]. In contrast to Harter's [2] finding, in which declines in intrinsic motivation indicate increases in extrinsic motivation, extrinsic motivation for reading, which was measured separately from intrinsic motivation, also declined in these children in Hong Kong [19]. Italian children's academic intrinsic motivation and academic performance (grades) decreased in the year from the end of primary school (5th grade) to the first year of middle school [20]. As mentioned earlier, Hungarian children's cognitive persistence and GPAs declined from 4th to 8th grade in a longitudinal study [7].

In Israel, researchers used Harter's [2] Intrinsic versus Extrinsic Orientation in the Classroom scale with large groups of third to ninth grade children who attended either "advantaged" or "disadvantaged" schools [21]. The children in the advantaged schools showed the typical decline in intrinsic motivation or increase in extrinsic motivation on Harter's "motivational" scales from third to ninth grade. However, again in contrast to Harter's findings, the children in the disadvantaged schools increased their self-ratings on these intrinsic motivation scales from grades 6 to 9 [21]. In Portugal, researchers studied intrinsic motivation related to mathematics classes in 5th to 12th grade students [22]. They found that younger children had higher selfratings of motivation compared to the older students. Spinath and Steinmayr [23] found longitudinal declines in German students' intrinsic motivation in general and in math, but not German language motivation, over a shorter one-year period from the end of second grade (age 9) to the end of third grade. In addition, in Hungary a decline in motivation to learn between grade 7 and grade 9 was found [24].

Thus, intrinsic motivation, in American children as well as those in other cultures and educational systems, often decreases during the years spent in school. However, the results are unclear because in many cases declines in intrinsic motivation were confounded with increases in extrinsic motivation. A decline has been found in several but not all domains of motivation. Thus, there is substantial evidence of a decrease in motivation from elementary school, perhaps between 3 rd and 6 th grade, until secondary school. However, clarification is needed as to whether this involves a decline in mastery motivation, a decline in academic (cognitive) mastery motivation only, a decline in intrinsic motivation, or an increase in extrinsic motivation. Is the decline in intrinsic motivation really mostly due to children's increasing understanding that extrinsic outcomes, such as grades, are important? Or are declines actually due to decreases in mastery motivation? These questions only can be determined if mastery motivation is disentangled from the intrinsic versus extrinsic source of motivation. Moreover, more information is needed regarding in which domains and environments mastery motivation does and does not show this decline. Although findings for math motivation are relatively consistent, many mastery domains have almost never been studied. This is important because there is evidence that mastery motivation is a strong predictor of school achievement $[7,12]$. To what extent is the decline in mastery motivation mainly in the domain of cognitive mastery and not other domains of mastery that are less closely related to school performance? And to what extent does the decline occur as a function of participation in school? This has important implications for school reform needs. To the extent that school systems differ across countries, this could help us understand the extent to which declines are associated with age rather than school practices. 
Furthermore, past studies were conducted with a variety of measures and ages across different cultures, so it is difficult to make cultural comparisons or know whether the age trends for the several different aspects of motivation are consistent across cultures. None of these studies have used the same instrument in two or more cultures. In addition, outside of Hungary, little has been published about age differences in aspects of mastery motivation.

1.4. Gender Differences in Mastery Motivation. We will examine gender differences in the present study given the possibility that culture and gender will interact in relation to differences in mastery motivation; however, our prediction is that there will be few such differences. A recent review found no statistically significant gender differences on the DMQ scales self-rated by Chinese and English speaking children [13]. There also were no significant differences between boys and girls according to teachers' ratings of these children. These nonsignificant gender/sex differences are similar to those found for a number of studies with behavioral mastery tasks [25]. However, there were gender differences in competence, favoring girls, based on both Chinese and American parent ratings. In the American sample, but not the Chinese, parents rated girls higher on social persistence with child peers. Even for these significant differences, effect sizes were small.

Hungarian investigations found no differences between boys' and girls' cognitive persistence based on students' selfreports or on teachers' or parents' reports [12]. However, with respect to social persistence with peers, girls were rated by all three types of Hungarian raters to be more strongly motivated. Similarly, social persistence with adults was also rated to be higher for girls. Student self-ratings of total mastery motivation did not reflect any gender-related differences, but parents and teachers rated girls significantly higher on total mastery motivation, with a small effect size. Given these findings, we decided to test for potential gender differences, but we predicted few large and consistent gender differences across cultures.

1.5. The Present Study. This paper examines age differences in student perceptions of each of five aspects of their mastery motivation across three quite different cultures, the United States, China, and Hungary. The study is important for three reasons. First, it is important to study whether there is a developmental decline on nonacademic dimensions or aspects of the mastery motivation on a measure in which intrinsic motivation is not contrasted with extrinsic motivation. Second, it is important to study both similarities and differences across countries in order to ascertain the generalizability of the effect despite different cultural and educational practices. Third, mastery motivation theory and some empirical evidence suggest that early indicators of mastery motivation are better predictors of later cognitive ability and performance than earlier mental development scores [26]. Recent studies using the DMQ have supported the conclusion that mastery motivation is a strong predictor of academic achievement [7,12]. Thus, declines in mastery motivation should have implications for later school performance and achievement in school and life, especially if there are major differences between the cultures in the decline. Moreover, if we find similar declines in nonacademic mastery domains, this may have implications for performance in other domains of development, such as sports or social and emotional competence.

1.6. Selection of the Three Specific Cultures for This Research. Students in these three countries were selected for several reasons. First, evidence to date regarding a decline in mastery motivation, as assessed by the DMQ, only had involved Hungarian children, so it was important to include a Hungarian sample both to replicate the prior findings and to make direct comparisons regarding the decline in Hungarian children versus children in other countries. Second, an American sample was needed because similar declines, but in intrinsic motivation, had been found in several studies. Thus, it was important to determine whether the same decline was found in American children's mastery motivation. Third, it seemed desirable to compare Chinese children to those in the United States and Hungary because an abundant literature suggests differences between Chinese and Western children in a variety of achievement-related variables $[19,27,28]$. This evidence did not include mastery motivation, so it is important to see if the finding holds for mastery motivation as well. Moreover, the existing study on age differences in intrinsic motivation in Asia involved children from Hong Kong, which is different in many ways due to the long-term influence of British culture in Hong Kong.

There are both similarities and differences between Hungarian, Chinese, and American school systems that may be pertinent to changes in motivation from elementary school to high school. First, important differences between China, the US, and Hungary include the actual curriculum, as well as the expectations of students [28-30]. American education is more varied than both Hungarian and Chinese education in curriculum, examination expectations, rigor, and concern about achievement and examinations. In both China and Hungary, entrance into more prestigious middle and high schools and curricula are often exam-based. Students' performance on major entrance exams usually determines the quality of education they receive in the next stage (middle school for Chinese students [and for a small group of Hungarians] and high school for both Chinese and Hungarian students). Because of such a cascading effect, students are under significant exam pressure throughout their education in China and in middle school (upper primary) in Hungary. In contrast, there are no entrance exams for public middle school or high school in the US; students need only have passing grades in order to be promoted to the next grade level. Moreover, although in recent years there also has been more emphasis on standardized tests for judging adequate yearly progress in the United States, the consequences are less important for the students themselves than in Hungary and, especially, China.

Second, sports and peer social activities/clubs play a larger part in the school and lives of American school children than children in China and Hungary, so it seems possible that there will be less decline in gross motor and social mastery with peers in the US than in China and Hungary. However, the literature does support a general 
decline in involvement in sports in secondary school for many children, so when nationality is not considered, gross motor mastery should show a decline.

Third, although, in general, adolescents increasingly value peer relationships over relationships with adults and should therefore show greater decline in motivation to master relationships with adults, this trend is likely to be less steep for Chinese youth, given the importance of respect for elders and filial piety in that culture [30].

Finally, a literature review related to Western versus Asian students' motivation to learn concluded that students in Asian cultures have stronger beliefs in the efficacy of effort in achievement. Chinese students are more likely to think that success depends on working hard (persistence) than Hungarian and other Western students do. In contrast, Western students are much more likely to think that aptitudes, capability, and talent are the key to success [28]. Based on this finding, along with the previously mentioned finding of the great importance of performance for future school placement, we predict that Chinese children should manifest lesser decline in cognitive persistence than Hungarian and especially American children. In contrast, given the greater focus on how well each child performs on entrance examinations in China, the emphasis in that culture on the importance of achievement, and the traditional Confucian emphasis on the need for constant self-improvement, we predict lower self-competence ratings in Chinese versus American and Hungarian students.

1.7. Research Hypotheses and Questions. The literature cited indicated a general decline in intrinsic motivation and related variables measured in several cultures, but decline in intrinsic motivation often was confounded with increase in extrinsic motivation. Mastery motivation does not require children or adults reporting on children to choose between intrinsic and extrinsic sources of motivation, focusing instead on the degree to which children are motivated to master skills and solve problems. Thus, the literature about intrinsic and extrinsic motivation is relevant but not conclusive for making predictions about age changes in mastery motivation.

The published mastery motivation literature about this decline in school children is limited to Hungarian children, so it is important to investigate whether children in other cultures experience the decline in mastery motivation at the same ages and on the same motivational dimensions. We tested four hypotheses and three research questions as follows.

(1) Based on the literature, our general, overall hypothesis is that children's self-perceptions of their mastery motivation will decrease from childhood to adolescence in all three cultures.

(2) We predict differences in the age trends for different dimensions of mastery motivation, with declines being greater on the cognitive persistence, gross motor persistence, and adult social persistence scales than on the peer social persistence and mastery pleasure scales.

(3) We predict there will also be a decline in self-perceived competence in all countries, but expect that perceived competence will be lower in China than in Hungary, and especially in the United States, particularly in secondary school.

(4) We predict that the declines in instrumental mastery motivation (persistence) will be greater in the US and Hungary than in China because of the perceived importance of effort/persistence for success in that culture.

(5) We expect to find similar levels of the five aspects of mastery motivation across cultures in primary school but greater cultural differences in secondary school. It seems possible that there will be lower levels of peer social and gross motor mastery motivation in China and Hungary than in the US in secondary school, given the greater emphasis in US schools on social and athletic skills. However, this hypothesis is tentative, given that even in the US fewer children remain involved in sports in high school than at younger ages. We also predict higher levels of cognitive mastery motivation in China than in the US and Hungary in secondary school given greater emphasis on persistence and achievement in school in China. Finally, we predict lesser decline in adult social persistence in Chinese students relative to the other two cultures.

(6) We ask how differentiated the five mastery motivation scales are and whether interscale correlations differ by culture.

(7) Finally, we explore whether there are gender differences on the DMQ scales, both across and between cultures.

\section{Method}

Independently, three sets of cross-sectional data were collected from 9,789 school age children between 7 and 19 years of age, during several studies in the US $(n=200)$, China $(n=1465)$, and Hungary $(n=8124)$, using six scales from the Dimensions of Mastery Questionnaire (DMQ).

2.1. The Dimensions of Mastery Questionnaire (DMQ). All three sets of data used the Dimensions of Mastery Questionnaire [11]. The Hungarian and Chinese DMQs were translated from the original English by the first and second authors, who were knowledgeable about research on mastery motivation and native speakers of the relevant language and who were also bilingual, with English as their second language. The DMQ was then back translated by another bilingual person not familiar with the DMQ. Discussion of possible translation problems and pilot testing took place before the translations were finalized and approved by the fourth author. Extended discussions of the development of the DMQ, its use to assess mastery motivation from infancy through high school and in several cultures, psychometric properties, and translation issues can be found in recent reviews $[6,12,13]$.

The DMQ used in these studies assesses children's selfperceptions of their own instrumental and expressive mastery related behaviors. Children rated how typical each behavior was for them on each of the 33 positively worded items using 
5-point Likert scales, with 1 indicating not at all typical and 5 as very typical. Psychometric properties for the three samples combined are given in this section; psychometrics for each country separately are provided under the method for each of the three studies.

The six scales, an aggregate of the four persistence scales, Cronbach alpha internal consistency reliabilities, and an example item used in these studies were as follows.

(1) Persistence at cognitive tasks (8 items, with an alpha for the total sample from all three countries of .76): for example, "I work on a new problem until I can do it well."

(2) Persistence at gross motor tasks (7 items, alpha .84): for example, "I try to do well in physical activities even when they are hard for me."

(3) Persistence at social tasks with adults (5 items, alpha .76); for example, "I enjoy talking with adults, and try to keep them interested."

(4) Persistence at social tasks with peers (5 items, alpha .69): for example "I try hard to make friends with other kids."

(5) Total persistence (25 items, alpha .89): this scale is the average of the four persistence scales.

(6) Mastery pleasure (5 items, alpha .76): for example, "I get excited when I figure something out."

(7) Self-perceived general competence (3 items; alpha .61): for example, "I solve problems quickly." This Competence scale is not considered to be a motivational measure, but rather a rating of the child's selfperceived ability.

Other examples of items are presented in Table 1, the whole sample factor analysis.

2.2. Data Analysis. To assess factorial validity, principal axis factor analyses with orthogonal rotation were computed on the data for the 30 mastery motivation items from each of the three countries separately and for the combined total sample. Table 1 shows the results of the analysis for the combined samples; the analyses for each country will be discussed in the Method section for that country. Notice in Table 1 that there is strong factorial evidence for the validity of the five mastery motivation scales because the mastery motivation items have their highest factor loading from the intended factor and there were no factors with cross loadings above .30. One intended cognitive persistence item (tries to do well on cause and effect activities) did not load on any scale. Thus, the four persistence scales and mastery pleasure all have good reliabilities and good factorial validity. This is also true for the data of each of the three cultures, as described later.

The self-perceived competence items were not included in the factor analysis because they were intended to measure self-ratings of the child's general cognitive ability rather than their mastery motivation. The competence scale correlated moderately highly with each of the five mastery motivation scales but most highly with cognitive persistence: $r=.51$ with cognitive persistence; .33 with gross motor; .33 with social with adults; .29 with social with peers; and .28 with mastery pleasure. These correlations indicate that school age children perceive a substantial overlap between their ability and, especially, their cognitive persistence/motivation.

There were also moderate to large correlations (varying from .29 to .69 with a median of .45) among the six mastery motivation scales, as shown in Table 2. This indicates that, on average, about $20 \%$ of the variance in each subscale was shared with other subscales. Although this can be interpreted as meaning the discriminant validity of the scales was not high, it could also be interpreted as meaning that children have systematic generalized differences in mastery motivation tendencies, even though there are also important differences across domains in these tendencies. The fact that the scales factored quite cleanly supports the latter interpretation. The scale intercorrelations were lowest for Hungarian students (median .42) and highest for Chinese students (median .54), indicating that Chinese children perceive themselves to have more interrelated or less differentiated mastery motivation and competence tendencies than the American and Hungarian students. This makes sense, given the emphasis in Chinese culture on persistence as the means of obtaining competence.

Within each sample, we computed a single factor (oneway) MANOVA with age group as the independent variable and the four persistence scales, mastery pleasure, and competence as dependent variables. If this was significant at $P<.01$, univariate $F$ s were examined, with Games-Howell post hoc tests, where appropriate $(\alpha=.01)$. Partial eta squared effect sizes were computed and interpreted as follows: .01-.05 = small, $.06-.13=$ medium, and .14 or more $=$ large [31]. Age group differences in total persistence were compared using one-way ANOVA.

Because gender could be an important variable, we initially did an age group $x$ gender MANOVA, with the six DMQ scales as dependent variables. However, only two of 18 age group $\mathrm{x}$ gender interactions were significant; they are described in the relevant results section. Thus, we decided to use the single factor (age group) MANOVA described above for the main analyses and tables. Separately, we computed one-way MANOVAs with gender as the independent variable.

To compare the three cultures at 11 and 16, the ages they had in common, we computed two MANOVAs for each age group. In the first of these, culture was the between groups factor and the four persistence scales were the dependent measures. In the second again culture was the between groups factor and the dependent variables were total persistence, mastery pleasure, and competence. When the MANOVA was significant, it was followed by univariate analyses, with Games-Howell post hoc comparisons. Alpha was set at .01, given the relatively large number of analyses. The results of these analyses are presented in Section 3, which follows description of each single-culture study.

\subsection{Study 1: American Children}

2.3.1. Subjects. The 200 American children (53\% males) were between 7 and 17 years old. They were predominantly from 
TABLE 1: Principal axis factor analysis of the combined American, Chinese, and Hungarian samples on the four persistence scales and mastery pleasure.

\begin{tabular}{|c|c|c|c|c|c|}
\hline Scales and items & $\begin{array}{l}\text { Gross motor } \\
\text { persist. }\end{array}$ & $\begin{array}{l}\text { Cognitive } \\
\text { persist. }\end{array}$ & $\begin{array}{l}\text { Mastery } \\
\text { pleasure }\end{array}$ & $\begin{array}{c}\text { Social persist. } \\
\text { adults }\end{array}$ & $\begin{array}{c}\text { Social persist. } \\
\text { peers }\end{array}$ \\
\hline \multicolumn{6}{|l|}{ Gross motor persistence } \\
\hline Likes sports and tries to do well & .706 & & & & \\
\hline Repeats sports skills to do well & .704 & & & & \\
\hline Tries to do well at athletics & .696 & & & & \\
\hline Tries to get better at catching & .564 & & & & \\
\hline Tries hard to throw well & .549 & & & & \\
\hline Tries hard to do well in physical activities & .535 & & & & \\
\hline Repeats motor skills to do well & .530 & & & & \\
\hline \multicolumn{6}{|l|}{ Cognitive persistence } \\
\hline Works long time to solve school problems & & .620 & & & \\
\hline Works a long time to do something hard & & .590 & & & \\
\hline Works on a problem until does it well & & .535 & & & \\
\hline Tries to complete school work & & .512 & & & \\
\hline Explores all ways to solve a problem & & .489 & & & \\
\hline Likes to try hard problems & & .468 & & & \\
\hline Tries to finish puzzles even if hard & & $<.30$ & & & \\
\hline \multicolumn{6}{|l|}{ Mastery pleasure } \\
\hline Is pleased when solving a hard problem & & & .671 & & \\
\hline Gets excited when figuring something out & & & .601 & & \\
\hline Gets excited when succeeding & & & .588 & & \\
\hline Smiles after finishing something & & & .509 & & \\
\hline Smiles when making something happen & & & .534 & & \\
\hline \multicolumn{6}{|l|}{ Social persistence with adults } \\
\hline Enjoys talking with adults & & & & .625 & \\
\hline Tries to interest adults in doing activities & & & & .600 & \\
\hline Enjoys discussing things with adults & & & & .543 & \\
\hline Likes to play with adults & & & & .541 & \\
\hline Tries to get adults to understand things & & & & .487 & \\
\hline \multicolumn{6}{|l|}{ Social persistence with peers } \\
\hline Tries to make friends with other kids & & & & & .568 \\
\hline Tries to get included in play with kids & & & & & .545 \\
\hline Likes to talk to other kids & & & & & .523 \\
\hline Tries to keep play with kids going & & & & & .430 \\
\hline Gets involved in pretend play with friends & & & & & .329 \\
\hline
\end{tabular}

Note. Principal axis factoring with varimax rotation. Eigenvalues $=7.87,2.20,1.68,1.62$, and 1.22 . These five factors account for $38.71 \%$ of the variance. Loadings less than .30 are not specified. The actual items were shortened to fit in the table.

middle-class families in two middle-sized cities in Colorado. These data were gathered for other studies and then divided into three age groups: $7-9,10-12$, and $13-17$ years old. The average age in each group was $7.80,10.76$, and 15.78 , thus, approximately 8,11 , and 16 years old. The children were either asked to complete the DMQ in a school classroom or given it individually as part of a testing session for a larger study. The items were read to the youngest children.

2.3.2. Measures. The five mastery motivation scales had Cronbach alphas from .67-.86 (median .80). Total persistence, the aggregate of the 4 persistence scales, had an even higher alpha (.90); and the general competence scale, with only 3 items, had the lowest alpha of the seven scales (.65).
The factor analysis for the American children was similar to that for the combined sample, except that persistence at social tasks with peers also included one gross motor (repeats motor skills to do them well) and one cognitive persistence item (tries to do well on cause and effect activities). One item on the social with peers scale (likes to talk to other kids) loaded just above $.30(.326)$ on the social with adults factor. All other items had their highest loading on the intended factor. Factor analyses of other larger samples of English speaking parents' ratings of their children have produced factor loadings even more consistent with the intended factors [13].

2.3.3. Results of the American Study. Table 3 presents the means, standard deviations, MANOVA, effect sizes, and age 
TABLE 2: Correlations among the DMQ scale scores for each culture separately and the total sample.

\begin{tabular}{|c|c|c|c|c|c|c|}
\hline Scales & Culture & $\begin{array}{l}\text { Cognitive } \\
\text { persistence }\end{array}$ & $\begin{array}{l}\text { Gross motor } \\
\text { persistence }\end{array}$ & $\begin{array}{c}\text { Social } \\
\text { persistence with } \\
\text { adults }\end{array}$ & $\begin{array}{c}\text { Social } \\
\text { persistence with } \\
\text { peers }\end{array}$ & Mastery pleasure \\
\hline \multirow{4}{*}{ Gross motor persistence } & US & .60 & - & - & - & - \\
\hline & $\mathrm{CH}$ & .69 & - & - & - & - \\
\hline & $\mathrm{HU}$ & .51 & - & - & - & - \\
\hline & Total & .53 & - & - & - & - \\
\hline \multirow{4}{*}{$\begin{array}{l}\text { Social persistence with } \\
\text { adults }\end{array}$} & US & .43 & .30 & - & - & - \\
\hline & $\mathrm{CH}$ & .51 & .48 & - & - & - \\
\hline & $\mathrm{HU}$ & .46 & .36 & - & - & - \\
\hline & Total & .45 & .38 & - & - & - \\
\hline \multirow{4}{*}{$\begin{array}{l}\text { Social persistence with } \\
\text { peers }\end{array}$} & US & .60 & .55 & .51 & - & - \\
\hline & $\mathrm{CH}$ & .64 & .58 & .53 & - & - \\
\hline & $\mathrm{HU}$ & .44 & .42 & .43 & - & - \\
\hline & Total & .46 & .45 & .46 & - & - \\
\hline \multirow{4}{*}{ Mastery pleasure } & US & .47 & .38 & .45 & .51 & - \\
\hline & $\mathrm{CH}$ & .54 & .46 & .33 & .52 & - \\
\hline & $\mathrm{HU}$ & .42 & .29 & .39 & .43 & - \\
\hline & Total & .44 & .31 & .38 & .44 & - \\
\hline \multirow{4}{*}{ Competence } & US & .48 & .31 & .25 & .21 & .21 \\
\hline & $\mathrm{CH}$ & .64 & .55 & .57 & .50 & .34 \\
\hline & $\mathrm{HU}$ & .48 & .29 & .29 & .26 & .27 \\
\hline & Total & .51 & .33 & .33 & .29 & .28 \\
\hline
\end{tabular}

group comparisons for the three age groups of American students. The results compare 16-, 11-, and 8- year-old children.

The American children's total persistence, cognitive persistence, gross motor persistence, and social persistence with peers were all found to decrease from middle childhood to adolescence. For all four of these measures, the effect size was large and the trend was the same: there was not a significant difference between 8 and 11, but these persistence ratings were higher at both of those ages than at 16 . However, no significant age differences on social persistence with adults, mastery pleasure, or general competence were found. The sharper decline in cognitive persistence and gross motor persistence was as predicted, but social persistence with peers also showed a significant decline.

There were no significant gender differences for the American sample at $P<.01$. Furthermore, there was no significant age $\mathrm{x}$ gender interaction from the two-way MANOVA.

\subsection{Study 2: Chinese Children}

2.4.1. Subjects. The 1465 Chinese children (54\% males) ranged between 10 and 19 years old. The Chinese data were from a national sample of representative regions with different levels of urbanicity. These data were gathered as part of an internet study of Chinese youth. The data were divided into three groups based on the child's grade in school, 4-6, $7-9$, or 10-12. The average age in each group was 11.03, 12.49, and 16.03 , which we label 11, 13, and 16 years old.
2.4.2. Measures. The five mastery motivation scales in this study had Cronbach alphas ranging from .75 to .87 (median .83). As expected, the aggregate of the four persistence scales, total persistence, had an even higher alpha (.92) and the shortest scale, competence, had the lowest (.64). The factor analysis of the Chinese children's data was again quite similar to the analysis of the combined samples, except two cognitive persistence items (tries to do well on cause and effect activities and tries to finish puzzles) factored with the items in the persistence at social tasks with peers items. All other items had their highest loading on the intended factor.

2.4.3. Results of the Chinese Study. The data analyses for the Chinese sample were the same as those used with the American sample. Table 4 presents the results in a format similar to those in Table 3 but compares 16-, 13-, and 11-yearold children.

The Chinese children's data showed a decline in all of the instrumental aspects of mastery motivation (total persistence, cognitive, gross motor, social persistence with adults, and social persistence with peers). In the Chinese sample, there was not a significant difference between ages 11 and 13 in total persistence, cognitive, gross motor, and social persistence with peers, but there was a decline from age 13 to 16 , early to later adolescence. Chinese children's social persistence with adults was highest at 11 and then decreased with a linear trend throughout adolescence. Consistent with the emphasis in Chinese culture on effort-based improvement, however, the effect sizes for age differences 
TABLE 3: Means, standard deviations, and comparisons of the three age groups of American children.

\begin{tabular}{|c|c|c|c|c|c|c|c|}
\hline DMQ scales & $\begin{array}{l}7-9 y \\
n=60\end{array}$ & $\begin{array}{l}10-12 y \\
n=40\end{array}$ & $\begin{array}{l}13-17 y \\
n=100\end{array}$ & $F$ & $P$ & Partial eta ${ }^{2}$ & $\begin{array}{c}\text { Age group } \\
\text { comparisons }\end{array}$ \\
\hline MANOVA & & & & 6.24 & $<.001$ & .19 & \\
\hline Cognitive persistence & $\begin{array}{c}4.08 \\
(0.72)\end{array}$ & $\begin{array}{c}4.02 \\
(0.64)\end{array}$ & $\begin{array}{c}3.36 \\
(0.68)\end{array}$ & 25.83 & $<.001$ & .21 & $8,11>16$ \\
\hline Gross motor persistence & $\begin{array}{c}4.27 \\
(0.79)\end{array}$ & $\begin{array}{c}4.38 \\
(0.59)\end{array}$ & $\begin{array}{c}3.59 \\
(0.95)\end{array}$ & 13.23 & $<.001$ & .16 & $8,11>16$ \\
\hline Social persistence with adults & $\begin{array}{c}3.51 \\
(1.03)\end{array}$ & $\begin{array}{c}3.67 \\
(0.79)\end{array}$ & $\begin{array}{c}3.28 \\
(0.82)\end{array}$ & 3.13 & .046 & .03 & $8,11,16$ \\
\hline Social persistence with peers & $\begin{array}{c}4.01 \\
(0.75)\end{array}$ & $\begin{array}{c}4.23 \\
(0.56)\end{array}$ & $\begin{array}{c}3.40 \\
(0.75)\end{array}$ & 24.22 & $<.001$ & .20 & $8,11>16$ \\
\hline Total persistence & $\begin{array}{c}3.97 \\
(0.63)\end{array}$ & $\begin{array}{c}4.07 \\
(0.49)\end{array}$ & $\begin{array}{c}3.41 \\
(0.61)\end{array}$ & 25.98 & $<.001$ & .21 & $8,11>16$ \\
\hline Mastery pleasure & $\begin{array}{c}4.13 \\
(0.79)\end{array}$ & $\begin{array}{c}4.05 \\
(0.75)\end{array}$ & $\begin{array}{c}3.82 \\
(0.88)\end{array}$ & 2.97 & .053 & .03 & $8,11,16$ \\
\hline Competence & $\begin{array}{c}3.93 \\
(0.90)\end{array}$ & $\begin{array}{c}3.86 \\
(0.87)\end{array}$ & $\begin{array}{c}3.65 \\
(0.70)\end{array}$ & 2.53 & .083 & .03 & $8,11,16$ \\
\hline
\end{tabular}

Note. Standard deviations are in parenthesis below the means. The 7-9- year-old group is labeled 8 in the age group comparisons column because their mean age was approximately 8 . Similarly, the 10-12-year- and the 13-17- year-old groups are labeled 11 and 16; 8, $11>16$ means there was no difference between 8 and 11-year old, but both were higher than 16 . A $P<.01$ was considered statistically significant.

TABLE 4: Means, standard deviations, and comparisons of the three age groups of Chinese children.

\begin{tabular}{|c|c|c|c|c|c|c|c|}
\hline \multirow[b]{2}{*}{ DMQ Scales } & \multicolumn{3}{|c|}{ Grade } & \multirow[b]{2}{*}{$F$} & \multirow[b]{2}{*}{$P$} & \multirow[b]{2}{*}{ Partial eta ${ }^{2}$} & \multirow{2}{*}{$\begin{array}{l}\text { Age group } \\
\text { comparisons }\end{array}$} \\
\hline & $\begin{array}{c}4-6 \\
n=236\end{array}$ & $\begin{array}{c}7-9 \\
n=718\end{array}$ & $\begin{array}{c}10-12 \\
n=511\end{array}$ & & & & \\
\hline MANOVA & & & & 17.23 & $<.001$ & .08 & \\
\hline Cognitive persistence & $\begin{array}{c}3.89 \\
(0.71)\end{array}$ & $\begin{array}{c}3.82 \\
(0.68)\end{array}$ & $\begin{array}{c}3.44 \\
(0.68)\end{array}$ & 58.40 & $<.001$ & .07 & $11,13>16$ \\
\hline Gross motor persistence & $\begin{array}{c}3.90 \\
(0.82)\end{array}$ & $\begin{array}{c}3.83 \\
(0.78)\end{array}$ & $\begin{array}{l}3.38 \\
(0.87)\end{array}$ & 54.15 & $<.001$ & .07 & $11,13>16$ \\
\hline Social persistence with adults & $\begin{array}{c}3.55 \\
(0.92)\end{array}$ & $\begin{array}{c}3.26 \\
(0.99)\end{array}$ & $\begin{array}{c}2.96 \\
(0.90)\end{array}$ & 34.90 & $<.001$ & .05 & $11>13>16$ \\
\hline Social persistence with peers & $\begin{array}{c}3.87 \\
(0.83)\end{array}$ & $\begin{array}{c}3.77 \\
(0.77)\end{array}$ & $\begin{array}{c}3.43 \\
(0.73)\end{array}$ & 39.49 & $<.001$ & .05 & $11,13>16$ \\
\hline Total persistence & $\begin{array}{c}3.80 \\
(0.70)\end{array}$ & $\begin{array}{c}3.67 \\
(0.66)\end{array}$ & $\begin{array}{c}3.30 \\
(0.62)\end{array}$ & 67.19 & $<.001$ & .08 & $11,13>16$ \\
\hline Mastery pleasure & $\begin{array}{c}4.02 \\
(0.83)\end{array}$ & $\begin{array}{c}4.07 \\
(0.79)\end{array}$ & $\begin{array}{c}4.01 \\
(0.77)\end{array}$ & 0.97 & .379 & .00 & $11,13,16$ \\
\hline Competence & $\begin{array}{c}3.69 \\
(0.81)\end{array}$ & $\begin{array}{c}3.49 \\
(0.85)\end{array}$ & $\begin{array}{c}3.04 \\
(0.75)\end{array}$ & 70.00 & $<.001$ & .09 & $11>13>16$ \\
\hline
\end{tabular}

Note. Standard deviations are given in parenthesis on the line below the means. The 10-11 y, 12-14 y, and 15-19 y age groups are labeled 11, 13, and 16, respectively, in the age group comparisons column because those were the approximate mean ages.

in these persistence scales were smaller than those for the American sample for all scales but social persistence with adults, ranging from small to medium. As with the American sample, there were no statistically significant age differences in mastery pleasure. Interestingly, the Chinese children's selfperceived competence decreased at each age, with a medium effect size.

For the Chinese children, there were significant gender differences on gross motor persistence and competence. Males rated themselves higher on these scales. When we did a two-way MANOVA, there was one age $\mathrm{x}$ gender interaction, for gross motor persistence. Not only were female students lower overall on this variable but also the gap was wider for the oldest (teenage) group.

\subsection{Study 3: Hungarian Children}

2.5.1. Subjects. The 8124 Hungarian children (49\% males) were in grades $2,4,6,8$, and 10 . They were representative of Hungarian children according to gender, geographical distribution, and parents' highest level of education. Data were collected as part of three cross-sectional studies planned 
to test the hypothesis that ratings of mastery motivation decline during this age period. The average age of Hungarian children in each of those grades was $8.8,10.85,12.93,14.91$, and 16.76 , which we have labeled as $9,11,13,15$, and 17 years old.

2.5.2. Measures. The five DMQ mastery motivation scales had Cronbach alphas ranging from .67, to .84 (median .74 ). The alphas were .88 for total persistence and .60 for competence. The factor analysis for the Hungarian children's data also provided strong support for the validity of the intended scales. All items except one (tries to do well on cause and effect activities), which did not load above .40 on any scale, had their highest loading on the intended scale.

2.5.3. Results of the Hungarian Study. The data analyses were the same as those for the American and Chinese samples and are shown in Table 5. All of the Hungarian children's instrumental/persistence mastery motivation scales and total persistence were found to decrease, with linear trends from childhood (age 9) to adolescence (age 17). The effect sizes were medium, except for total persistence, which was large. In addition there was a linear decline in the self-ratings of mastery pleasure from 9 to 13. There was no difference from 13 to 15 but then a small but significant increase in mastery pleasure at 17. Hungarian children's self-perceived competence was not different across ages, except that the second graders (age 9) rated themselves slightly higher than children at the older ages (small effect size).

For the Hungarian children, five of the seven DMQ variables showed gender differences, in part due to the very large samples and high power of the analyses. Boys rated themselves higher on gross motor persistence and competence, while Hungarian girls rated themselves higher on social persistence with adults, with peers, and mastery pleasure. The only age $\mathrm{x}$ gender interaction was for gross motor persistence, where the gap between girls and boys ratings was biggest in the teen years.

\section{Results Related to the Research Hypotheses and Questions}

(1) Our basic hypothesis was that there would be a general decline in all three cultures on both the instrumental/persistence and the affective dimensions of mastery motivation. This hypothesis was largely confirmed for persistence but there were mixed results for mastery pleasure.

Figure 1 and Tables 3-5 show the decline in total persistence for the three cultures. The age trends were quite similar in all three cultures, especially the downward trend from age 11 or 13 to later adolescence. The declines were also seen in all three cultures separately on three of the four instrumental motivational measures: cognitive persistence, gross motor persistence, and social persistence with peers. The Chinese and Hungarian children also showed a decline on social persistence with adults. Although the American children's mean scores, similarly, were somewhat lower for the adolescent age group, the decline in social persistence with adults was not statistically significant at $P<.01$ for

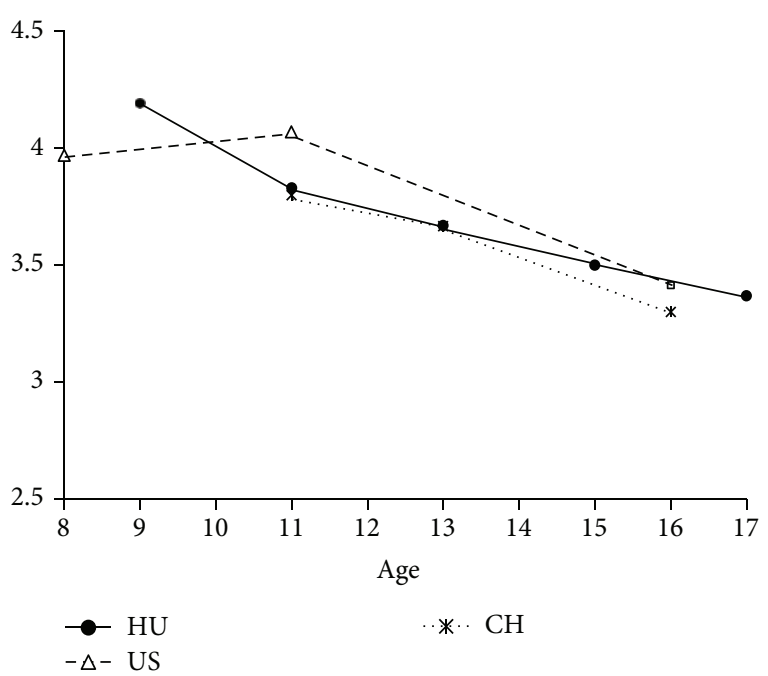

Figure 1: Age changes in TOTAL persistence for American, Chinese, and Hungarian students.

Americans, perhaps in part due to the smaller American sample relative to the other two samples.

The trends for mastery pleasure were less clear, and varied across cultures. The Chinese and American samples had no significant age differences, while in the very large Hungarian sample there was a significant decrease in these self-ratings of mastery pleasure from 9 to 13. In all samples, though, the effect size for age effects on mastery pleasure was small.

(2) The second hypothesis predicted different amounts of decline on the several dimensions of mastery motivation, with cognitive and gross motor persistence predicted to decrease more than the social mastery motivation scales and mastery pleasure. This hypothesis was largely confirmed, because in all three cultures the effect sizes for cognitive and gross motor persistence were larger than these for the two social mastery scales, and in all three cultures changes in mastery pleasure had the smallest effect size.

(3) The third hypothesis predicted a decline in selfperceived competence in all countries, but that perceived competence would be lower in China, especially in secondary school. Results indicated that the three cultures differed considerably in degree of decline on perceived competence. There was not a significant decline in the American competence ratings, and although there was a significant decline in the Hungarian ratings from second grade until fourth grade, after second grade they were essentially flat. There was, however, a significant linear decline in the Chinese sample, although with a small effect size.

There were significant cultural differences in selfperceived competence at both 11 and 16 (see Table 6). At 11 the Chinese children rated themselves as more competent than the Hungarians (but not the Americans) did; however, at 16 , the Chinese teens rated their competence as lower than both the Hungarian and American teens, and the Americans rated themselves as more competent than the Hungarians. This is consistent with the prediction that the Chinese self-perceptions of their competence would be significantly lower than the other cultures at age 16 (secondary school). 
TABlE 5: Means, standard deviations, and comparisons of the five age groups of Hungarian children.

\begin{tabular}{|c|c|c|c|c|c|c|c|c|}
\hline \multirow[b]{2}{*}{ DMQ scales } & \multicolumn{5}{|c|}{ Grade } & \multirow[b]{2}{*}{$F$} & \multirow[b]{2}{*}{ eta $^{2}$} & \multirow{2}{*}{$\begin{array}{l}\text { Age group } \\
\text { comparisons }\end{array}$} \\
\hline & $\begin{array}{c}2 \\
n=754\end{array}$ & $\begin{array}{c}4 \\
n=2558\end{array}$ & $\begin{array}{c}6 \\
n=1435\end{array}$ & $\begin{array}{c}8 \\
n=1388\end{array}$ & $\begin{array}{c}10 \\
n=1989\end{array}$ & & & \\
\hline MANOVA & & & & & & 103.2 & .08 & \\
\hline Cognitive persistence & $\begin{array}{c}4.03 \\
(0.68)\end{array}$ & $\begin{array}{c}3.68 \\
(0.64)\end{array}$ & $\begin{array}{c}3.47 \\
(0.64)\end{array}$ & $\begin{array}{c}3.26 \\
(0.63)\end{array}$ & $\begin{array}{c}3.25 \\
(0.57)\end{array}$ & 315.7 & .14 & $\begin{array}{c}9>11>13> \\
15,17\end{array}$ \\
\hline Gross motor persistence & $\begin{array}{c}4.31 \\
(0.68)\end{array}$ & $\begin{array}{l}4.08 \\
(0.75)\end{array}$ & $\begin{array}{c}3.86 \\
(0.80)\end{array}$ & $\begin{array}{c}3.59 \\
(0.90)\end{array}$ & $\begin{array}{c}3.36 \\
(0.88)\end{array}$ & 322.0 & .14 & $\begin{array}{c}9>11>13> \\
15>17\end{array}$ \\
\hline Social persistence with adults & $\begin{array}{c}4.12 \\
(0.78)\end{array}$ & $\begin{array}{c}3.61 \\
(0.84)\end{array}$ & $\begin{array}{c}3.42 \\
(0.83)\end{array}$ & $\begin{array}{c}3.30 \\
(0.82)\end{array}$ & $\begin{array}{c}3.24 \\
(0.74)\end{array}$ & 199.1 & .09 & $\begin{array}{c}9>11>13> \\
15,17\end{array}$ \\
\hline Social persistence with peers & $\begin{array}{c}4.32 \\
(0.72)\end{array}$ & $\begin{array}{c}3.96 \\
(0.70)\end{array}$ & $\begin{array}{c}3.92 \\
(0.69)\end{array}$ & $\begin{array}{c}3.86 \\
(0.67)\end{array}$ & $\begin{array}{c}3.65 \\
(0.65)\end{array}$ & 141.4 & .07 & $\begin{array}{c}9>11,13,15> \\
17\end{array}$ \\
\hline Total persistence & $\begin{array}{c}4.19 \\
(0.57)\end{array}$ & $\begin{array}{c}3.83 \\
(0.54)\end{array}$ & $\begin{array}{c}3.67 \\
(0.55)\end{array}$ & $\begin{array}{c}3.50 \\
(0.54)\end{array}$ & $\begin{array}{c}3.37 \\
(0.49)\end{array}$ & 423.6 & .17 & $\begin{array}{c}9>11>13> \\
15>17\end{array}$ \\
\hline Mastery pleasure & $\begin{array}{c}4.28 \\
(0.72)\end{array}$ & $\begin{array}{c}3.97 \\
(0.78)\end{array}$ & $\begin{array}{c}3.82 \\
(0.83)\end{array}$ & $\begin{array}{c}3.88 \\
(0.78)\end{array}$ & $\begin{array}{l}4.08 \\
(0.71)\end{array}$ & 55.4 & .03 & $\begin{aligned} 9>11 & >13,15 \\
& <17\end{aligned}$ \\
\hline Competence & $\begin{array}{c}3.78 \\
(0.88)\end{array}$ & $\begin{array}{c}3.28 \\
(0.80)\end{array}$ & $\begin{array}{c}3.26 \\
(0.73)\end{array}$ & $\begin{array}{c}3.20 \\
(0.68)\end{array}$ & $\begin{array}{c}3.22 \\
(0.60)\end{array}$ & 97.6 & .05 & $\begin{array}{c}9>11,13,15 \\
17\end{array}$ \\
\hline
\end{tabular}

Note. Standard deviations are in parenthesis below the means. The Hungarian children in grades 2, 4, 6, 8, and 10 had average approximate mean ages of 9, 11, 13,15 , and 17 so those are used in the age group comparison column. All overall $F$ s were significant at $P<.001$.

(4) This hypothesis predicted greater decline in persistence for the American and Hungarian children than for the Chinese. In general this was supported. The significant decline in total persistence for the American and Hungarian children had large effect sizes (partial eta ${ }^{2}=.21$, and .17 , resp.), while this decline for the Chinese sample was a medium effect size (.08).

(5) We expected to find similar levels of the five aspects of mastery motivation across cultures at 11 but greater cultural differences at age 16 . To examine this prediction, we compared the three cultures separately at ages 11 and 16 , where all three cultures had data (Table 6). On total persistence at age 11, the overall difference was not significant at $P<.01$ (see also Figure 1). In contrast, at age 16 the overall difference was significant. This increase in cultural differences at age 16 for overall persistence was consistent with prediction. The American and Hungarian teens rated themselves higher than the Chinese teens rated themselves on total persistence. Thus, the aggregated persistence scores were more similar in the three cultures at age 11 than at 16.

However, although the general trend for persistence was consistent with prediction, there were some differences across the three cultures that were inconsistent with this general trend. The Hungarian children rated themselves the lowest on cognitive persistence at both 11 and 16. For gross motor motivation, the Americans rated themselves the highest and Chinese rated lowest at age 11, but there were no cultural differences at 16 . There were significant cultural differences, with small effect sizes, at both 11 and 16 on social mastery motivation with peers. At 11, the American children rated themselves higher than both the Hungarian and Chinese children did. However, at 16 the Hungarians rated themselves the highest on social mastery with peers; at both ages the Chinese were low on this dimension. Finally, with regard to mastery pleasure, there were no significant cultural differences.
(6) The six mastery motivation scales and competence were less highly correlated in Hungarian and American students than Chinese students, which is consistent with prior evidence that Chinese students have a stronger belief that effort/persistence is important and that it is the way to achieve competence.

(7) Finally, we asked about gender differences on each of the six scales and between cultures. Males rated themselves higher than females in China and Hungary but not the US on gross motor persistence and competence. Hungarian girls, but not American or Chinese girls, rated themselves higher on mastery pleasure and the two social persistence scales. However, these significant gender differences had small effect sizes. Thus, as found in most mastery motivation research, gender differences were small and inconsistent across samples $[12,13]$.

\section{Discussion}

4.1. Age Declines in Motivation. Our overall hypothesis was that there would be a general decline in all three cultures on both the instrumental/persistence and the affective dimensions of mastery motivation. This hypothesis was largely confirmed for persistence but there were mixed results for mastery pleasure. The current age-related declines in motivation are consistent with those found in a longitudinal study with Hungarian children [7] and in studies of academic intrinsic motivation in American children $[1,17,18]$. However, this is the first study that demonstrated a decline in mastery motivation across three different countries using the same measure.

An extension of these findings can be found in data reported by Morgan et al. [13], which included DMQ selfratings by Chinese 3rd to 6th grade primary school children. These self-ratings of children from a middle-sized city in Southern China showed a significant decline from 9 to 11 
TABLE 6: Means and comparisons of the three cultures at several common ages on the DMQ scales.

\begin{tabular}{|c|c|c|c|c|c|c|c|}
\hline DMQ scales ages & US & China & Hungary & $F$ & $P$ & Partial eta $^{2}$ & Cultural comparisons \\
\hline \multicolumn{8}{|c|}{ Cognitive persistence } \\
\hline Age 11 & 4.02 & 3.89 & 3.68 & 15.74 & $<.001$ & .01 & $\mathrm{US}, \mathrm{CN}>\mathrm{HU}$ \\
\hline Age 16 & 3.36 & 3.44 & 3.25 & 21.19 & $<.001$ & .01 & $\mathrm{CN}, \mathrm{US}>\mathrm{HU}$ \\
\hline \multicolumn{8}{|c|}{ Gross motor persistence } \\
\hline Age 11 & 4.38 & 3.90 & 4.08 & 9.42 & $<.001$ & .01 & $\mathrm{US}>\mathrm{HU}>\mathrm{CN}$ \\
\hline Age 16 & 3.59 & 3.38 & 3.47 & 2.72 & .066 & .00 & - \\
\hline \multicolumn{8}{|c|}{ Social persistence with adults } \\
\hline Age 11 & 3.67 & 3.55 & 3.61 & .59 & .554 & .00 & - \\
\hline Age 16 & 3.28 & 2.96 & 3.27 & 33.80 & $<.001$ & .02 & $\mathrm{US}, \mathrm{HU}>\mathrm{CN}$ \\
\hline \multicolumn{8}{|c|}{ Social persistence with peers } \\
\hline Age 11 & 4.23 & 3.87 & 3.96 & 4.68 & .009 & .00 & $\mathrm{US}>\mathrm{HU}, \mathrm{CN}$ \\
\hline Age 16 & 3.40 & 3.43 & 3.75 & 55.46 & $<.001$ & .03 & $\mathrm{HU}>\mathrm{CN}$, US \\
\hline \multicolumn{8}{|l|}{ Total persistence } \\
\hline Age 11 & 4.07 & 3.80 & 3.83 & 3.95 & .019 & .00 & - \\
\hline Age 16 & 3.41 & 3.30 & 3.43 & 12.50 & $<.001$ & .01 & $\mathrm{US}, \mathrm{HU}>\mathrm{CN}$ \\
\hline \multicolumn{8}{|l|}{ Mastery pleasure } \\
\hline Age 11 & 4.05 & 4.02 & 3.97 & 5.51 & .577 & .00 & - \\
\hline Age 16 & 3.82 & 4.01 & 3.98 & 2.86 & .057 & .00 & - \\
\hline \multicolumn{8}{|c|}{ General competence } \\
\hline Age 11 & 3.86 & 3.69 & 3.28 & 38.78 & $<.001$ & .03 & $\mathrm{US}, \mathrm{CN}>\mathrm{HU}$ \\
\hline Age 16 & 3.65 & 3.04 & 3.21 & 41.40 & $<.001$ & .02 & $\mathrm{US}>\mathrm{HU}>\mathrm{CN}$ \\
\hline
\end{tabular}

Note. At each age, a MANOVA was computed for the four persistence scales and a separate MANOVA was computed for total persistence, mastery pleasure, and competence at 11 and also at 16. If significant, they were followed by univariate ANOVAs and Games-Howell post hoc tests when appropriate.

years of age on all four persistence measures but not on mastery pleasure or competence. These declines in persistence seem to be earlier than in the Chinese children in the current study, where we saw insignificant decreases between 11 and 13 .

Thus, considering the current data and other DMQ data, we conclude that there is a decline in persistence in all three cultures from about ages 10-13 to 16 . However, the decline may begin a little earlier in Hungary and a little later in America and perhaps in China. Effect sizes indicate larger declines for cognitive and gross motor persistence than on the social dimensions in all three cultures but especially in Hungary.

The additional Chinese 3rd to 6th grade data are consistent with the current study; there were no changes for Chinese primary school students on mastery pleasure or competence from 9-11 [13]. It appears that the Chinese students' decline in self-rated competence that we saw in the current data does not start until about age 11 . Remember that there were no differences in American or Hungarian students' competence ratings between 11 and 16 .

The findings of the large study in Israel [21] were interesting; students from the several advantaged schools rated their intrinsic motivation similarly to our Hungarian students, declining from 3rd to 9th grades, while those in the disadvantaged schools had very different age trends than those in our three cultures, with actual increases in selfperceived intrinsic motivation from 6 th to 9 th grade. There are many possible explanations for the discrepant findings, including the different ethnic makeup of the disadvantaged school population and the fact that the researchers used the Harter measure, which requires one to choose internal versus external sources of motivation. It is possible that the children in the disadvantaged schools saw themselves as very different from their teachers and therefore did not wish to perform well to please their teachers or even felt like their teachers had unfavorable beliefs about them. The findings should be replicated using a measure such as the DMQ that does not require choice between intrinsic and extrinsic sources of motivation.

In contrast to findings for persistence, there was little evidence of an important decline in mastery pleasure with age. The Chinese and American samples had no significant age differences, and although in the very large Hungarian sample there was a significant decrease in these self-ratings of mastery pleasure from 9 to 13 , the effect size for age differences on mastery pleasure was small. These discrepant findings suggest that the reduced persistence is not likely a result of reduced tendency to derive pleasure from successful mastery. It is unclear what factors are responsible for the drop in mastery motivation; however, the robust evidence of this decline suggests that additional research is needed to determine its causes and implications. It seems plausible that increased difficulty and time intensiveness of schoolwork with age contribute to the reduced mastery motivation. As indicated earlier, there is some evidence that decreased perceived competence is associated with later decreased motivation, which is consistent with the idea that difficulty level plays a role in decreased motivation. 
4.2. Differential Decline on Different Domains of Mastery. The second hypothesis predicted different amounts of decline on the several dimensions of mastery motivation, with cognitive, gross motor, and adult social persistence predicted to decrease more than the peer social mastery motivation scales and mastery pleasure. This hypothesis was partially confirmed because in all three cultures the effect sizes for cognitive and gross motor persistence were larger than these for the two social mastery scales, and in all three cultures changes in mastery pleasure had the smallest effect size. Again, as children progress through higher levels of education, the expectations and difficulty levels increase for school-related skills and athletic achievement, which plausibly presents adolescents with difficulty levels that exceed the moderate level of challenge that is associated with highest mastery motivation. However, surprisingly, American children's peer social persistence decreased significantly and adult social persistence did not. Moreover, Chinese children's adult social persistence decreased more than American children's, which is contrary to expectation. Although at first glance, the decline in social mastery motivation with peers seems to be contrary to the widespread finding that peer relationships show increased importance in adolescence, this may have in part been due to the relatively simple/developmentally young interests and skills assessed by that subscale, such as keeping interactions going, engaging in pretend play, and getting involved in peers' play. The well-documented increase in the importance of peer relationships during adolescence may be more about increased intimacy than the characteristics sampled in the DMQ. The DMQ was devised to be as similar as possible from infancy to adolescence, but this may have led to less developmentally appropriate skills for adolescents than younger children. A newer version of the DMQ with different items for adolescents' social mastery motivation with peers at the older ages has now been developed, and further research is needed to see how these changes impact developmental change from childhood to adolescence in peer social persistence.

4.3. Cross-Cultural Differences in Perceived Competence. We also predicted that there would be a decline in self-perceived competence in all countries, but that perceived competence would be lower in China at age 16 than in Hungary and especially in the United States. Results showed that the three cultures differed considerably in age differences in perceived competence. There was not a significant decline in the American or Hungarian competence ratings, and although there was a significant difference between the two youngest age groups given the extremely large number of participants, the Hungarian ratings were very similar across age, and the effect size was small. There was, however, a significant linear decline with a medium effect size in the Chinese sample. The decline in perceived competence in Chinese adolescents was predicted, based on the greater emphasis and feedback on test performance in that culture, along with the cultural emphasis on academic achievement and the need to continuously improve oneself. This contrasts with Western cultures, which value self-esteem and try not to emphasize performance difficulties children might show.
4.4. Greater Decline in Persistence in Western Children Than Chinese. The next hypothesis predicted greater decline for the American and Hungarian children than for the Chinese, based on the emphasis in Asian culture on the importance of effort/persistence. In general this prediction was supported. This lesser decline in persistence has important implications for Chinese students' continued growth in school and may be one of the reasons for studies indicating greater math performance by Asian children, given the need for effort and persistence in mastering mathematics. Further research is needed to examine the relation between motivation and performance in different subjects in Eastern and Western countries.

4.5. Greater Cultural Differences at Age 16 Than Age 11. We expected to find greater cultural differences in mastery motivation at age 16 than at age 11, and there was some support for this prediction. When the four persistence scales were aggregated, cultural differences were greater at age 16 than at age 11. However, there also were a few inconsistencies on particular scales. Hungarian children rated themselves the lowest on cognitive persistence at both ages. For gross motor motivation, there were no cultural differences at age 16. There were significant cultural differences, with small effect sizes, at both 11 and 16 on social mastery motivation with peers. Thus, our prediction was not supported consistently, although results for overall persistence were consistent with our hypothesis. One limitation of this study was that, by comparing cultures on the same measure, we may have omitted measurement of aspects of mastery motivation that are specific to the different cultures. Several recent papers (e.g., [32]) have highlighted the need to take an "emic" approach, in which one ascertains culture-specific characteristics by obtaining in-depth information from members of that culture, rather than only examining "etic" characteristics that are expected to be relevant to all of the cultures studied. Further research is needed, taking this emic approach to determine potential sources of cross-cultural differences in motivation that are pertinent to age-related changes.

4.6. Correlations among DMQ Subscales in the Three Cultures. The six mastery motivation scales and competence correlated in all samples, but they were less highly correlated in Hungarian and American students than Chinese students. This is consistent with prior evidence that Chinese students have a stronger belief that effort/persistence is important and that it is the way to achieve competence. Nevertheless, the factorial validity of the subscales, along with the findings of differential decline in different subscales, supports the value of examining different domains of mastery separately. Further research is needed to examine the importance of these differences in agerelated trends in different domains of mastery motivation, as well as of the higher interrelatedness of the domains in Chinese children.

4.7. Gender Differences in Mastery Motivation. In general, gender differences on the DMQ scales were rare and small. Males rated themselves higher than females in China and Hungary but not the US on gross motor persistence and competence. Hungarian girls, but not American or Chinese 
girls, rated themselves higher on mastery pleasure and the two social persistence scales. However, these significant gender differences had small effect sizes. Thus, as found in most mastery motivation research, gender does not seem to be a large influence on mastery motivation $[12,13]$.

4.8. Limitations. Although both the Hungarian and Chinese versions of the DMQ were translated, back translated, and reconciled before use in these studies, there are always concerns about whether there is linguistic equivalence. The similarity of the factor analysis and the Cronbach alphas in three languages provided some support for such equivalence. However, the factor analysis indicates a few items did not work well in all three cultures, although this probably is in part due to smaller sample size in the American and Chinese samples.

The most obvious strength of the use of questionnaires in all the research cited in this paper is the ease of data collection and the resulting larger samples sizes. However, children's self-perceptions may be influenced not only by their actual motivation but also by characteristics of their personalities and by response biases. Nevertheless, self-perceptions of mastery motivation are important in themselves because these perceptions undoubtedly influence interactions with teachers, parents, and peers as well as influencing their work in school.

The Hungarian data were specifically designed to assess age differences in children's mastery motivation with nationally representative samples of children in grades $2,4,6$, 8 , and 10 assessed in their classrooms. The Chinese and especially the American children had more variability in procedures, and the US had smaller age-group samples with less equal Ns and generally larger standard deviations within each age group, making comparisons at the various ages across cultures difficult. There were few variables other than age, gender, and the DMQ scales common across samples so we are not able to identify other variables that might be contributing to the age declines and cultural differences. It is also impossible to determine to what extent the implicit "average person" to whom children were comparing themselves differed across cultures, and whether this played a role in children's judgments of their own level of motivation or competence. To the extent that most children are more persistent in China, for example, children might have rated their own persistence lower than they would have if the "average" child was less persistent.

Finally, there were very different sample sizes for the different cultures, with the Hungarian sample being particularly large and the American sample being particularly small. Some of the differences across the three within-culture analyses may have been due to these differences in sample size, and findings for the American sample might be less robust than those for the other two countries.

4.9. Conclusions and Implications. The results of this study indicate a robust finding of a decline in mastery motivation from primary school until high school in three disparate cultures. A number of possibilities have been proposed to explain such a developmental trend. For example, as children grow, they become more realistic in their competence and motivational perceptions, and they even may become overly pessimistic about their mastery interactions [27, 32, 33]. It also may be that children in grades 1 and 2 may not fully understand the questions even when the items are read to them. However, the parallel declines in parent and teacher ratings [12] suggest that young children's higher self-ratings in early elementary school cannot be due only to being unrealistic or having a deficit in understanding. These teacher and parent ratings also indicate that the age changes reported in this paper were not merely a function of generally more negative self-perceptions among teens. Teachers and parents see a similar age decline in motivation.

At developmental transitions from elementary school to middle school and from middle school to high school, school work and social relationships both provide heightened challenges. These transitions can lead to declines in grades which may in turn lead to a decline in motivation. However, the lack of decline in self-perceptions of competence in the US and Hungarian samples during these transitions is not consistent with this explanation. Children who have a fixed mindset about competence tend to make less effort on challenging tasks because they can attribute potential failure to their lack of effort or persistence rather than a lack of competence [33]. Chinese children are at higher risk of declining self-perceptions of competence because Chinese adults tend to criticize children as a whole person rather than for specific mistakes. Chinese parents also emphasize failure more than success; thus, Chinese children respond less positively to success and more negatively to failure as compared to American children [27]. Different views between many Eastern and Western cultures about learning processes may lead to different mindsets in children and influence their perceptions of competence and effort. Many Eastern cultures see struggle as a natural part of learning and provide opportunities for improvement. But in many Western societies, struggle is associated with the lack of competence, leading to the development of a fixed mindset.

Some possible educational implications of these findings are the importance of emphasizing effort and persistence at schoolwork, as well as the value of succeeding in school, especially by Western teachers, given evidence of a strong relationship between mastery motivation and performance in school. It also is important for teachers to recognize potential cultural differences in attitude toward perceived competence. An emphasis on self-esteem may at times even undermine persistence and performance, to the extent that students exert less effort in order to excuse their poor performance and preserve their self-esteem.

4.10. Future Research. More research is needed to clarify how culture and other environmental factors influence children's motivational trajectory. More studies with a longitudinal design also are needed to reveal the mechanisms through which these changes occur. Future research should use confirmatory factor analysis to assess measurement invariance in the DMQ across cultures. Such analyses could lead to revisions of the DMQ with some items deleted and others changed. 


\section{Conflict of Interests}

The authors declare that there is no conflict of interests regarding the publication of this paper.

\section{Acknowledgment}

This research was supported by Hungarian Scientific Research Fund, OTKA-K83850.

\section{References}

[1] A. E. Gottfried, J. S. Fleming, and A. W. Gottfried, "Continuity of academic intrinsic motivation from childhood through late adolescence: a longitudinal study," Journal of Educational Psychology, vol. 93, no. 1, pp. 3-13, 2001.

[2] S. Harter, "A new self-report scale of intrinsic versus extrinsic orientation in the classroom: motivational and informational components," Developmental Psychology, vol. 17, no. 3, pp. 300312, 1981.

[3] M. R. Lepper, J. H. Corpus, and S. S. Iyengar, "Intrinsic and extrinsic motivational orientations in the classroom: age differences and academic correlates," Journal of Educational Psychology, vol. 97, no. 2, pp. 184-196, 2005.

[4] A. E. Gottfried, G. A. Marcoulides, A. W. Gottfried, and P. Oliver, "Longitudinal pathways from math intrinsic motivation and achievement to math course accomplishments and educational attainment," Journal of Research on Educational Effectiveness, vol. 6, no. 1, pp. 68-92, 2013.

[5] J. P. Shonkoff and D. Phillips, From Neurons to Neighborhoods: The Science of Early Childhood Development, National Academies Press, Washington, DC, USA, 2000.

[6] N. A. Busch-Rossnagel and G. A. Morgan, "Introduction to the mastery motivation and self-regulation section," in Handbook of Self-Regulatory Processes in Development: New Directions and International Perspectives, K. C. Barrett, N. A. Fox, G. A. Morgan, D. J. Fidler, and L. A. Daunhauer, Eds., pp. 247-264, Psychology Press, New York, NY, USA, 2013.

[7] K. Jozsa and G. A. Morgan, "Developmental changes in cognitive persistence and academic achievement between grade 4 and grade 8," European Journal of Psychology of Education, vol. 29, no. 3, pp. 521-535, 2014.

[8] R. W. White, "Motivation reconsidered: the concept of competence," Psychological Review, vol. 66, no. 5, pp. 297-333, 1959.

[9] L. J. Yarrow, J. L. Rubenstein, and F. A. Pedersen, Infant and Environment: Early Cognitive and Motivational Development, John Wiley \& Sons, Washington, DC, USA, 1975.

[10] K. C. Barrett and G. A. Morgan, "Continuities and discontinuities in mastery motivation during infancy and toddlerhood: a conceptualization and review," in Mastery Motivation: Origins, Conceptualizations, and Applications, R. H. MacTurk and G. A. Morgan, Eds., pp. 57-93, Ablex, Westport, Conn, USA, 1995.

[11] G. A. Morgan, "Dimensions of Mastery Questionnaire," Database Record, PsycTESTS, 1997.

[12] K. Jozsa and E. D. Molnar, "The relationships between mastery motivation, self-regulated learning, and school success: a Hungarian and wider European perspective," in Handbook of Self-Regulatory Processes in Development: New Directions and International Perspectives, K. C. Barrett, N. A. Fox, G. A. Morgan, D. J. Fidler, and L. A. Daunhauer, Eds., pp. 265-304, Routledge, New York, NY, USA, 2013.
[13] G. A. Morgan, J. Wang, H. F. Liao, and Q. Xu, "Using the dimensions of mastery questionnaire to assess mastery motivation of English- and Chinese- speaking children: psychometrics and implications for self-regulation," in Handbook of Self-Regulatory Processes in Development: New Directions and International Perspectives, K. C. Barrett, N. A. Fox, G. A. Morgan, D. J. Fidler, and L. A. Daunhauer, Eds., pp. 305-335, Psychology Press, New York, NY, USA, 2013.

[14] K. Jozsa, "Developing new scales for assessing English and German language mastery motivation," in Studies in Honour of Marianne Nikolov, J. Horvath and P. Medgyes, Eds., pp. 37-50, Lingua Franca Csoport, Pécs, Hungary, 2014.

[15] K. Jozsa, J. Hricsovinyi, and B. Szenczi, "Számítógép-alapú Elsajátítási motiváció kérdőívek validitása és reliabilitása," in Online diagnosztikus mérések az iskola kezdő szakaszában, B. Csapo and A. Zsolnai, Eds., Nemzedékek Tudása Tankönykiadó, Budapest, Hungary, In press.

[16] K. Jozsa, B. Szenczi, and N. Kis, "The computer based version of SDQ I. Self-concept questionnaire," in Proceedings of the 14th Hungarian National Conference on Education, Debrecen, Hungary, November 2014.

[17] A. E. Gottfried, "Academic intrinsic motivation in elementary and junior high school students," Journal of Educational Psychology, vol. 77, no. 6, pp. 631-645, 1985.

[18] A. E. Gottfried, G. A. Marcoulides, A. W. Gottfried, P. H. Oliver, and D. W. Guerin, "Multivariate latent change modeling of developmental decline in academic intrinsic math motivation and achievement: childhood through adolescence," International Journal of Behavioral Development, vol. 31, no. 4, pp. 317327, 2007.

[19] K.-L. Lau, "Grade differences in reading motivation among Hong Kong primary and secondary students," British Journal of Educational Psychology, vol. 79, no. 4, pp. 713-733, 2009.

[20] M. Zanobini and M. C. Usai, "Domain-specific self-concept and achievement motivation in the transition from primary to low middle school," Educational Psychology, vol. 22, no. 2, pp. 203$217,2002$.

[21] D. Tzuriel, "Development of motivational and cognitive-informational orientations from third to ninth grades," Journal of Applied Developmental Psychology, vol. 10, no. 1, pp. 107-121, 1989.

[22] M. L. Mata, V. Monteiro, and F. Peixoto, "Attitudes towards mathematics: effects of individual, motivational, and social support factors," Child Development Research, vol. 2012, Article ID 876028, 10 pages, 2012.

[23] B. Spinath and R. Steinmayr, "Longitudinal analysis of intrinsic motivation and competence beliefs: is there a relation over time?” Child Development, vol. 79, no. 5, pp. 1555-1569, 2008.

[24] K. Jozsa, “Tanulási motiváció és humán műveltség," in Az iskolai müveltség, B. Csapo, Ed., pp. 239-268, Osiris Kiadó, Budapest, Hungary, 2002.

[25] G. A. Morgan and R. K. Yang, "Toward a conceptualization of the organization of mastery motivation," in Mastery Motivation: Origins, Conceptualizations, and Applications, R. H. MacTurk and G. A. Morgan, Eds., pp. 317-337, Ablex, Norwood, NJ, USA, 1995.

[26] L. J. Yarrow, R. P. Klein, S. Lomonaco, and G. A. Morgan, "Cognitive and motivational development in early childhood," in The Exceptional Infant 3: Assessment and Intervention, B. Z. Friedlander, G. M. Sterritt, and G. Kirk, Eds., pp. 491-502, Bruner/Mazel, New York, NY, USA, 1975. 
[27] F. Fei-Yin Ng, E. M. Pomerantz, and S.-F. Lam, "European American and Chinese parents' responses to children's success and failure: Implications for children's responses," Developmental Psychology, vol. 43, no. 5, pp. 1239-1255, 2007.

[28] J. Gordon-Gyori, "Kulturális különbségek a tanulási motivációban," Magyar Pszichológiai Szemle, vol. 64, no. 1, pp. 203228, 2009.

[29] A. Imre and G. Zoltan, "The educational system and the progression of students," in Education in Hungary 2006, Z. Loboda, J. Lannert, and G. Halász, Eds., pp. 45-66, Hungarian Institute for Educational Research and Development, Budapest, Hungary, 2007.

[30] "Instructional Systems," National Center on Education and the Economy, http://www.ncee.org/programs-affiliates/center-on-international-education-benchmarking/top-performing-countries/shanghai-china/shanghai-china-instructionalsystems/.

[31] N. L. Leech, K. C. Barrett, and G. A. Morgan, IBM SPSS for Intermediate Statistics, Routledge, New York, NY, USA, 4th edition, 2011.

[32] D. J. Stipek and D. H. Daniels, "Declining perceptions of competence: a consequence of changes in the child or in the educational environment?" Journal of Educational Psychology, vol. 80, no. 3, pp. 352-356, 1988.

[33] C. S. Dweck, "The development of ability conceptions," in Development of Achievement Motivation, A. Wigfield and J. S. Eccles, Eds., pp. 57-88, Academic Press, San Diego, Calif, USA, 2002. 

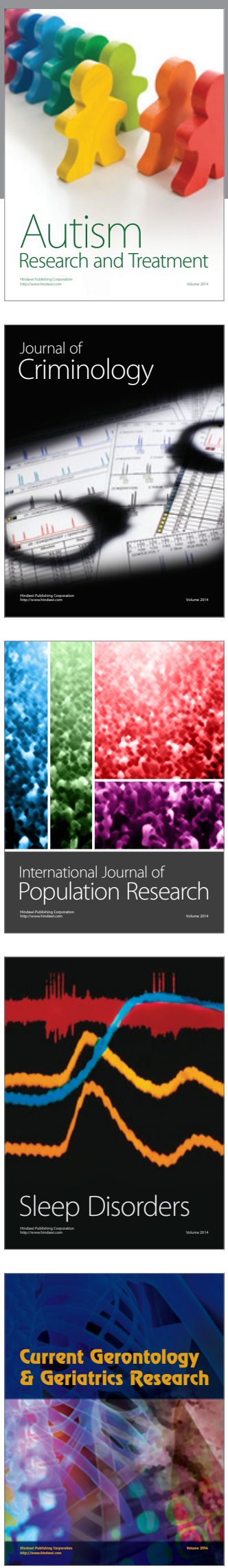
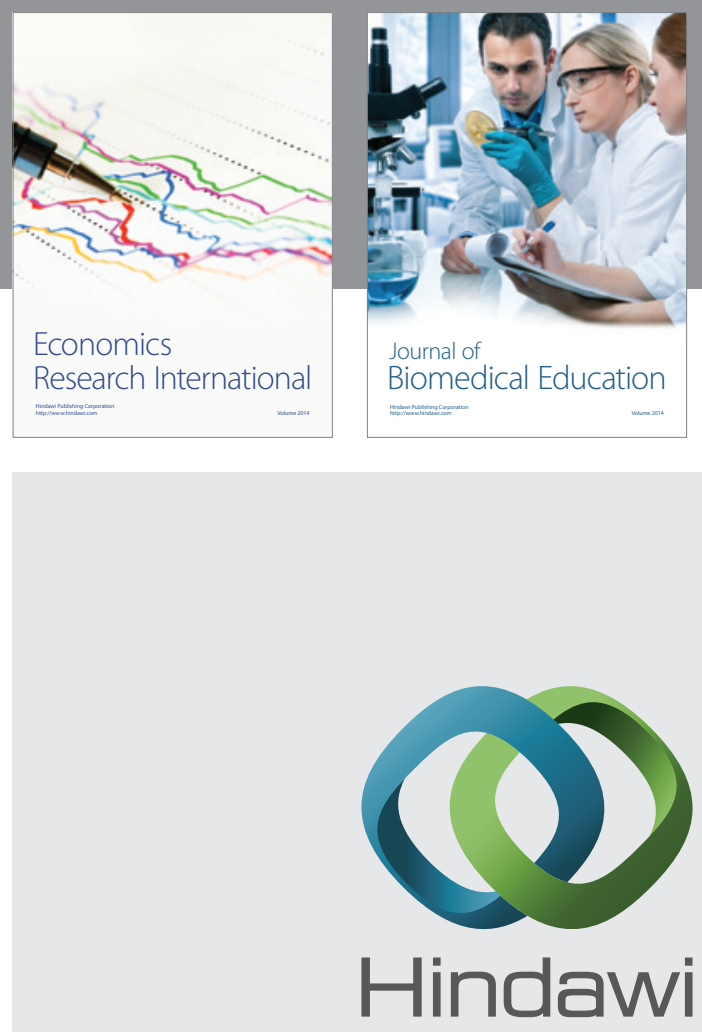

Submit your manuscripts at

http://www.hindawi.com
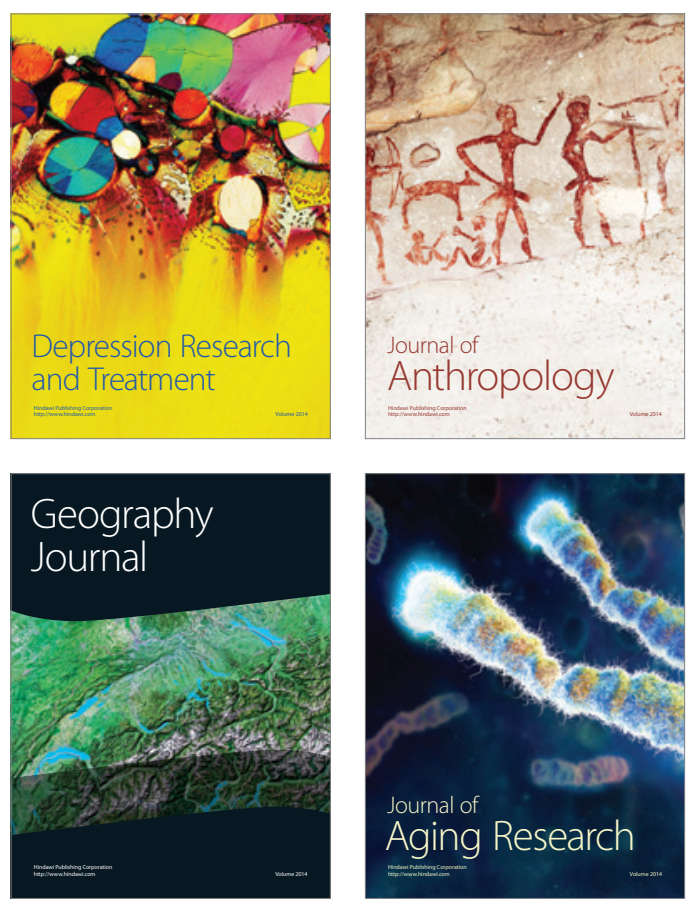
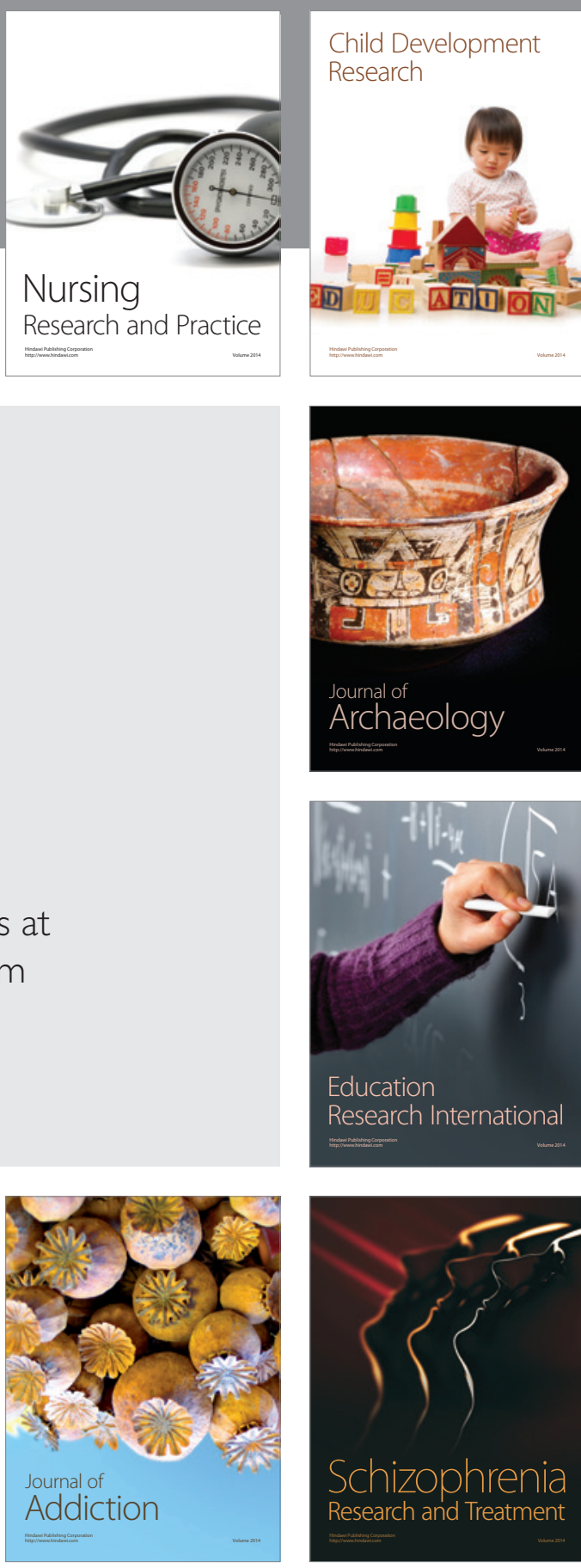

(D)
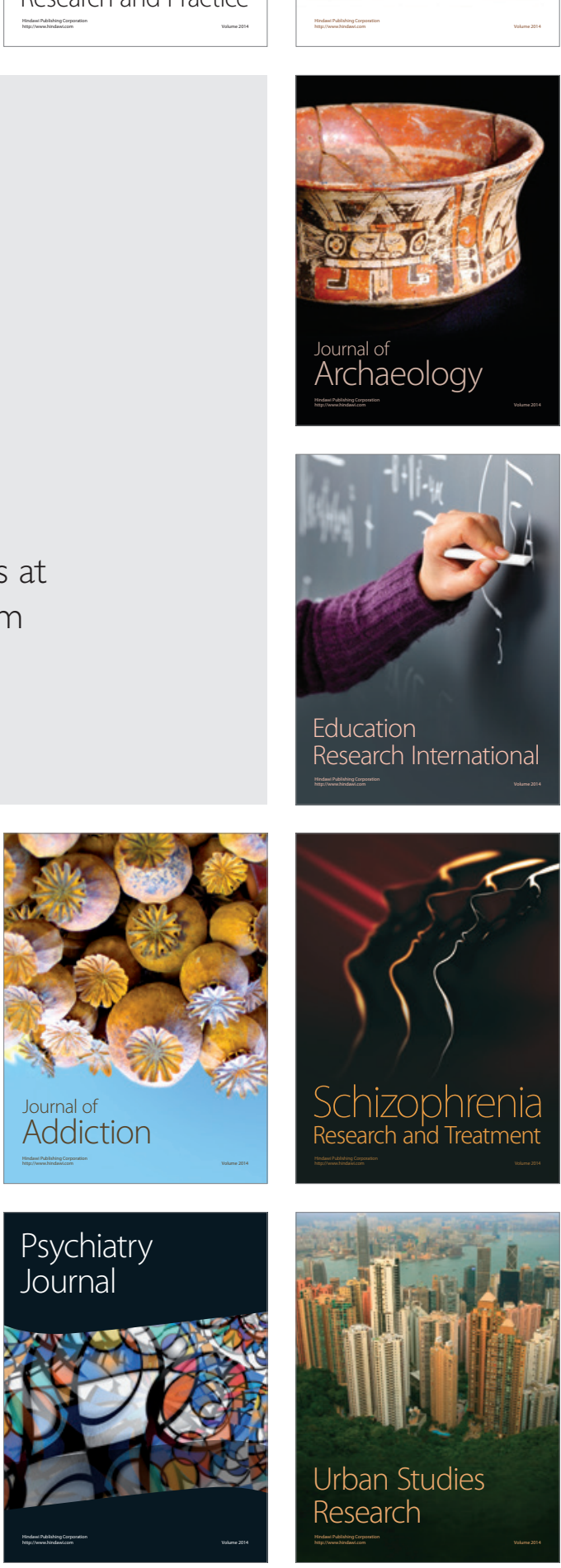